\title{
A study on abuse of topical corticosteroids in patients who attended dermatology venerology leprosy outpatient department
}

\author{
R. Sarathi ${ }^{1 *}$, A. Christypriya ${ }^{1}$, P. K. Kaviarasan ${ }^{2}$, Guru Prasad Mohanta ${ }^{1}$
}

\begin{abstract}
${ }^{1}$ Department of Pharmacy, FEAT, Annamalai University, Annamalai Nagar, Tamil Nadu, India
${ }^{2}$ Department of DVL, RMMCH, Annamalai University, Annamalai Nagar, Tamil Nadu, India
\end{abstract}

Received: 03 September 2020

Revised: 19 September 2020

Accepted: 21 September 2020

\section{*Correspondence:}

Dr. R. Sarathi,

Email: parthasarathyramalingam@gmail.com

Copyright: (C) the author(s), publisher and licensee Medip Academy. This is an open-access article distributed under the terms of the Creative Commons Attribution Non-Commercial License, which permits unrestricted non-commercial use, distribution, and reproduction in any medium, provided the original work is properly cited.

\section{ABSTRACT}

Background: Topical corticosteroids (TCs) are widely used in the patients affected with dermatoses. Abuse of these agents may cause severe adverse effects. Aim of the study was to study the abuse of TCs in patient who attend Dermatology, Venereology, and Leprosy (DVL) outpatient department.

Methods: This prospective observational study was conducted in department of DVL at Rajah Muthiah Medical college, Tamil Nadu during the period of six months from November 2018 to April 2019. The patients were enrolled for the study based on inclusion and exclusion criteria.

Results: Totally 50 patients with adverse drug reactions (ADRs) by the abuse of TCs were enrolled for the study. It was found that TCs were abused in all ages and equally in both genders. Nearly $72 \%$ of the people used TCs for Tinea infection and $20 \%$ of the people used TCs for acne vulgaris. Very high potent TCs such as betamethasone and beclomethasone were abused by $55 \%$ of the patient. Tinea incognito (TI) was found as common ADRs by the abuse of TCs $(74 \%)$. Nearly $88 \%$ of the people bought TCs from pharmacies without prescription. Sixteen brands were found as easily accessible and affordable for the patients. Medication adherence were increased by $60 \%$ after the patient counselling.

Conclusion: This study concludes, TI was found as a common ADR in patients who abused TCs such as betamethasone, beclomethasone and clobetasol. High potent TCs should not be allowed to dispense without prescription. Withdrawal of TCs will reduce the risk of ADRs.

Keywords: TC, ADR, TI, Betamethasone, Clobetasol

\section{INTRODUCTION}

TCs are used commonly for the dermatose patients. ${ }^{1}$ Betamethasone, clobetasol are 10 and 50 times stronger than hydrocortisone vice versa. ${ }^{2}$ TCs are classified based on their potency (mild, moderate, potent, high potent). ${ }^{3}$ Potency of the TCs is determined by the Lipophilicity of the compound. TCs with different compositions are easily available in the market as an over the counter (OTC) products. $^{4-6}$
TCs are used for treating the disease conditions like dermatophytosis, acne vulgaris, tinea corporis, tinea cruris, melasma, pyoderma, psoriasis and skin bleaching. ${ }^{7-9}$ Inappropriate use or prolonged use of these agents may lead to severe ADRs like epidermal and dermal atrophy, acne, folliculitis, miliaria, rosacea, hypertrichosis, hypopigmentation, allergic contact dermatitis, masking or aggravation of dermatophytosis, scabies. ${ }^{10-12}$ Severity of the ADR is related to the duration of the treatment and potency of the TCs. 
The aim of this study was to study the abuse of TCs in patients who attend DVL outpatient department. The main objectives are to observe the complications of TCs used by the patients who attend DVL outpatient department; to observe the extent of use of corticosteroids; to determine the risk of prolonged use of corticosteroids; to identify, document and assess the ADRs if any; to provide patient counselling to improve the medication adherence.

\section{METHODS}

This prospective observational study was conducted in department of DVL at Rajah Muthiah Medical College Hospital (RMMCH), Annamalai University, Annamalai Nagar, Tamil Nadu during the period of six months from November 2018 to April 2019. Patients who attended DVL outpatient department with the complaints of dermatoses due to topical corticosteroid application as without prescription or by physician were enrolled for the study after obtaining their signed consent form. Patients or legal representatives who was not willing to participate were excluded from the study. The data was collected using designed data collection form.

History of the illness, name and ingredients of the preparation, purpose of the use, duration of the treatment, source of the prescription, frequency of application, nature of the lesion, size, shape and region of the lesion were recorded by the proforma. ${ }^{13,14}$ Dermatoses were diagnosed by the cutaneous examination and potassium hydroxide $(\mathrm{KOH})$ mount positivity test for the needed patients. Photos were taken in some patients with their consent.

The risks and ADRs of prolonged use of corticosteroids were documented by using the ADR reporting form of national pharmacovigilance program (PvPI). The data was analyzed using excel sheets.

\section{RESULTS}

Totally 50 patients were enrolled for the study $(n=50)$. The study shows that $48 \%$ of the people are aged between 21-40 years and $38 \%$ of the people aged between $0-20$ years. Both genders equally used TCs (male-24 patients and female-26 patients). It shows that $74 \%$ of the people were literate and $76 \%$ of the people were from Urban area. It concludes that $74 \%$ of the patients were poor. So, they bought TCs without prescription (Table 1).

Most of the patients $(\mathrm{n}=41)$ used TCs for Tinea corporis $(62 \%)$ and Acne vulgaris $(20 \%)$ (Table 2). Betamethasone (31\%) and Beclomethasone (24\%) causes most of the ADRs documented. Only 5 patients were used two are more TCs (Table 3).

TI $(74 \%)$ was the most common ADR of the TCs abuse. Acne form eruption (12\%) was secondary ADR of TCs abuse (Table 4, Figure1). The study shown that tinea corporis (28 patients) is mostly associated with tinea incognito which means patients abused TCs for tinea corporis but they developed tinea incognito (Table 5).

Most of the TCs were abused for tinea corporis infections (31 patients) (Table 6). It concludes that most of the TCs caused tinea incognito infection (37 patients). Mainly betamethasone (13 patients) and beclomethasone (11 patients) caused tinea incognito infection. Acne form eruption developed only in patients $(n=11)$ with abuse of mometasone, halobetasol and betamethasone (Table 7).

Table 1: Demographic data of the patients with abuse of TCs.

\begin{tabular}{|ll|}
\hline Parameters & No. of patients $(\%)$ \\
\hline Age (years) & $19(38)$ \\
\hline $0-20$ & $24(48)$ \\
\hline $21-40$ & $5(10)$ \\
\hline $41-60$ & $2(4)$ \\
\hline$>60$ & \\
\hline Gender & $24(48)$ \\
\hline Male & $26(52)$ \\
\hline Female & \\
\hline Education & $13(26)$ \\
\hline Primary & $20(40)$ \\
\hline SSLC/HSC & $17(34)$ \\
\hline College & \\
\hline Residence & $38(76)$ \\
\hline Urban & $12(24)$ \\
\hline Rural & \\
\hline Socioeconomic status & $37(74)$ \\
\hline Poor & $10(20)$ \\
\hline Middle Class & $3(6)$ \\
\hline High Class & \\
\hline
\end{tabular}

Table 2: Reasons for the use of TCs application by the patients.

\begin{tabular}{|ll|}
\hline Indication & No. of patients $(\%)$ \\
\hline Tinea corporis & $31(62)$ \\
\hline Acne vulgaris & $10(20)$ \\
\hline Tinea cruris & $5(10)$ \\
\hline Skin rash & $3(6)$ \\
\hline Contact dermatitis & $1(2)$ \\
\hline
\end{tabular}

Table 3: Causes of ADRs (name of TCs).

\begin{tabular}{|ll|}
\hline Name of TCs & No. of patients $(\%)$ \\
\hline Betamethasone $\mathbf{0 . 1 \%}$ & $17(31)$ \\
\hline Beclomethasone $\mathbf{0 . 0 2 5} \%$ & $13(24)$ \\
\hline Clobetasol 0.05\% & $8(15)$ \\
\hline Mometasone 1\% & $9(16)$ \\
\hline Halobetasol $0.05 \%$ & $2(3)$ \\
\hline Others & $6(11)$ \\
\hline
\end{tabular}

* the percentages in the name of TCs denotes the strength of the topical corticosteroids. five patients were used more than two TCs. so, the total number of patients will come as 55 . 
Table 4: ADRs of TCs abused by the patients.

\begin{tabular}{|ll|}
\hline ADRs & No. of patients $(\%)$ \\
\hline Tinea incognito & $37(74)$ \\
\hline Pellagroid rash & $3(6)$ \\
\hline Hypopigmentation & $2(4)$ \\
\hline Acne form eruption & $6(12)$ \\
\hline Irritant contact dermatitis & $1(2)$ \\
\hline others & $1(2)$ \\
\hline
\end{tabular}

Table 5: Association of ADRs with indications.

\begin{tabular}{|c|c|c|c|c|c|c|}
\hline Indications & TI & Pellagroid rash & $\begin{array}{l}\text { Hypopig- } \\
\text { mentation }\end{array}$ & $\begin{array}{l}\text { Acne form } \\
\text { eruption }\end{array}$ & $\begin{array}{l}\text { Irritant contact } \\
\text { dermatitis }\end{array}$ & Others \\
\hline \multicolumn{7}{|l|}{ ADRs } \\
\hline Tinea corporis & 28 & - & 2 & - & - & 1 \\
\hline Tinea cruris & 5 & - & - & - & - & - \\
\hline Acne vulgaris & 4 & - & - & 6 & - & - \\
\hline Skin rash & - & 3 & - & - & - & - \\
\hline Contact dermatitis & - & - & - & - & 1 & - \\
\hline
\end{tabular}

Table 6: Association of indications with abuse of TCs.

\begin{tabular}{|c|c|c|c|c|c|}
\hline Indications & Tinea corporis & Tinea cruris & Acne vulgaris & Skin rash & Contact Dermatitis \\
\hline \multicolumn{6}{|l|}{ Name of TCs } \\
\hline Beclomethasone & 8 & 1 & 4 & - & - \\
\hline Betamethasone & 12 & 1 & 3 & - & 1 \\
\hline Clobetasol & 5 & 3 & - & - & - \\
\hline Mometasone & - & - & 6 & 3 & - \\
\hline Halobetasol & - & - & 2 & - & - \\
\hline Others & 6 & - & - & - & - \\
\hline
\end{tabular}

*five patients were used more than two TCs. so, the total number of patients will come as 55 .

Table 7: Association of ADRs with abuse of topical corticosteroids (TCs).

\begin{tabular}{|c|c|c|c|c|c|c|}
\hline Name of TCs & Betamethasone & Beclomethasone & Clobetasol & Mometasone & Halobetasol & Others \\
\hline \multicolumn{7}{|l|}{ ADRs } \\
\hline TI & 13 & 11 & 7 & - & - & 6 \\
\hline Acne form eruption & 3 & - & - & 6 & 2 & - \\
\hline Pellagroid rash & - & - & - & 3 & - & - \\
\hline $\begin{array}{l}\text { Irritant contact } \\
\text { dermatitis }\end{array}$ & 1 & - & - & - & - & - \\
\hline Hypopigmentation & - & 2 & - & - & - & - \\
\hline Others & - & - & 1 & - & - & - \\
\hline
\end{tabular}

*five patients were used more than two TCs. so, the total number of patients will come as 55 .

It concludes that $66 \%$ of the patients bought the TCs without prescription (Table 8). The study shown that medication adherence was increased $(60 \%)$ in patients after the patient counselling (Figure 2).

Average cost for treating ADRs per patient (497.00 INR) is very higher than average cost of TCs abused per patient (78.00 INR). It concludes that $72 \%$ of cost was increased for treating ADRs instead of treating the disease.

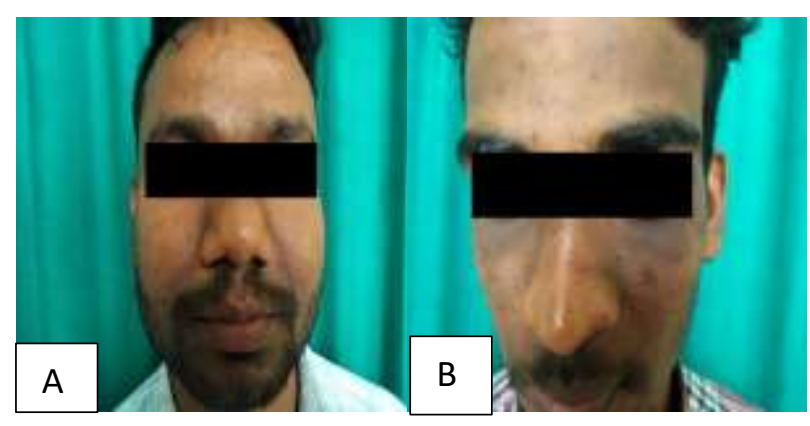

Figure 1: (A) Hypopigmentation and (B) TI. 


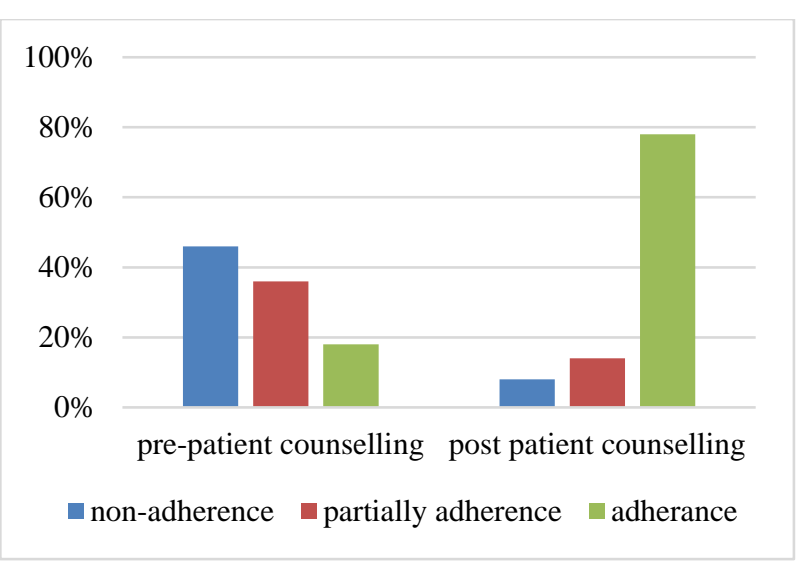

Figure 2: Medication adherence score.

Table 8: Source of information.

\begin{tabular}{|ll|}
\hline Source & No. of patients $(\%)$ \\
\hline Without prescription & $33(66)$ \\
\hline Physician & $6(12)$ \\
\hline Friends/relatives & $11(22)$ \\
\hline
\end{tabular}

\section{DISCUSSION}

Totally 50 patients with ADRs by the abuse of TCs were enrolled for the study. All of them abused TCs more than a month. It was found that TCs were abused in all ages and equally in both genders. Nearly $74 \%$ of the people were literate (most of them were students). Most of the people were from urban area $(76 \%)$.

The patients with ADRs may higher when compared with similar studies and it may possible because we only included the patients with ADRs by the abuse of TCs. The mean age of the patients with TCs abuse was 11-30 years. Gender, duration of the TCs abuse, literacy and residence of the patients were nearly similar to other studies. $^{4}$

Nearly $72 \%$ of the people used TCs for fungal infections like tinea corporis and tinea cruris and $20 \%$ of the people used TCs for acne vulgaris. Others $(8 \%)$ used TCs for skin rash and Contact Dermatitis (CD). Similar studies conclude that most of the patients $( \pm 50 \%)$ were used TCs for skin lightening, acne and dermatophytosis. ${ }^{5}$

Very high potent TCs such as betamethasone and beclomethasone were abused by $55 \%$ of the patient. It was nearly similar in some studies and some studies were conclude that clobetasol was commonly abused by a greater number $(\geq 50 \%)$ of patients. ${ }^{6,7}$

Totally 6 ADRs were found from the patients with the abuse of TCs. Tinea incognito or steroid induced hyperpigmentation was found as common ADRs by the abuse of TCs (74\%). Only $2 \%$ of the people developed irritant contact dermatitis. Acne form eruptions, tinea incognito and telangiectasia was the most common ADRs in some other studies $( \pm 40 \%){ }^{8}$

This study newly concludes that nearly 33 patients $(66 \%)$ abused TCs for tinea infections but they developed TI. Betamethasone, beclomethasone and clobetasol were abused by $56 \%$ of the patients for tinea infections. Two or more corticosteroids (mometasone, halobetasol, betamethasone) were abused by $10 \%$ of the patients.

TI is common ADRs in patients with abuse of betamethasone and beclomethasone (44\%). Acne form eruption was developed only in patients $(20 \%)$ with abuse of mometasone, halobetasol and betamethasone.

Nearly $88 \%$ of the people bought TCs from pharmacies without prescription. Medication adherence were increased by $60 \%$ after the patient counselling. Majority $(74 \%)$ of them were found as poor people.

Sixteen brands were found as easily accessible and affordable for the patients. Approximately one patient spent $14 \%$ of the cost for TCs from total cost of the medication. But they spent $72 \%$ extra for treating the ADRs that developed by the abuse of TCs.

\section{CONCLUSION}

This study concludes that TI was found as a common ADR in patients who abused TCs such as betamethasone, beclomethasone and clobetasol. High potent TCs should not be allowed to dispense without prescription. Withdrawal of TCs will reduce the risk of ADRs. Continuous or prolonged use of TCs may worsen the side effects. Continuous education should be provided to physicians, pharmacists, nurses and other health care professionals about the effects of TCs. Awareness should be created to the people about the risk of abusing TCs. Consulting a dermatologist for skin infections will reduce the risk of abuse of TCs.

Limitations: The study period was limited to six months. Only few pictures were taken after getting the informed consent form from the patients.

\section{ACKNOWLEDGEMENTS}

Author would like to thanks to Prof. Dr. P.V.S. Prasad, Assoc. Prof. Dr. K. Kannambal, Asst. Prof. Dr. B. Poorana, Department of DVL, RMMCH, Annamalai University and all the post graduate students for their valuable cooperation and suggestions for carryout our work in successful manner.

Funding: No funding sources

Conflict of interest: None declared

Ethical approval: The study was approved by Institutional Human Ethics Committee [IHEC]. Approval no: IHEC/0388/2018. 


\section{REFERENCES}

1. Tripathi KD. Drugs acting on skin and mucous membranes. In: Tripathi KD, editor. Essentials of medical pharmacology, $8^{\text {th }}$ ed. New Delhi: Jaypee Brothers Medical Publishers; 2019;954-56.

2. Abdul WA, Desai N. Eczema and psoriasis. In: Walker R, Whittlesea C, editor. Clinical pharmacy and therapeutics, $5^{\text {th }}$ ed. Edinburgh: Churchill Livingstone/Elsevier; 2014;896.

3. Satoskar RS, Rege N, Bhandarkar SD. Adrenal cortical steroids. In: Satoskar RS, editor. Pharmacology and pharmacotherapeutics. $24^{\text {th }}$ ed. Mumbai: Elsevier, 2015;930-2.

4. Meena S, Gupta LK, Khare AK, Balai M, Mittal1 A, Mehta S et al. Topical Corticosteroids Abuse: A Clinical Study of Cutaneous Adverse Effects. Indian J Dermatol. 2017;62:675.

5. Sharma R, Abrol S, Wani M. Misuse of topical corticosteroids on facial skin. A study of 200 patients. J Dermatol Case Rep. 2017;11:5-8.

6. Dey VK. Misuse of topical corticosteroids: A clinical study of adverse effects. Indian Dermatol Online J. 2014;5:436-40.

7. Chaudhary RG, Rathod SP, Jagati A, Baxi K, Ambasana A, Patel D. Prescription and Usage Pattern of Topical Corticosteroids among Out-patient Attendees with Dermatophyte Infections and Its Analysis: A Cross-sectional, Survey-based Study. Indian Dermatol Online J. 2019;10:279-83.

8. Saraswat A, Lahiri K, Chatterjee M, Barua S, Coondoo A, Mittal A et al. Topical corticosteroid abuse on the face: a prospective, multicenter study of dermatology outpatients. Indian J Dermatol Venereol Leprol. 2011;77:160-6.

9. Rathi SK, D'Souza P. Rational and ethical use of topical corticosteroids based on safety and efficacy. Indian J Dermatol. 2012;57:251-9.

10. Das A, Das D, Das NK. Topical corticosteroid abuse. Indian Pediatr. 2014;51:162.

11. Jain S, Mohapatra L, Mohanty P, Jena S, Behera B. Study of Clinical Profile of Patients Presenting with Topical Steroid-Induced Facial Dermatosis to a Tertiary Care Hospital. Indian Dermatol Online J. 2020;11:208-11.

12. Pal D, Biswas P, Das S, De A, Sharma N, Ansari A. Topical Steroid Damaged/Dependent Face (TSDF): A Study from a Tertiary Care Hospital in Eastern India. Indian J Dermatol. 2018;63:375-9.

13. Bhat YJ, Manzoor S, Qayoom S. Steroid-induced rosacea: a clinical study of 200 patients. Indian J Dermatol. 2011;56:30-32.

14. Mahar S, Mahajan K, Agarwal S, Kar HK, Bhattacharya SK. Topical Corticosteroid Misuse: The Scenario in Patients Attending a Tertiary Care Hospital in New Delhi. J Clin Diagn Res. 2016;10:FC16-20.

Cite this article as: Sarathi R, Christypriya A, Kaviarasan PK, Mohanta GP. A study on abuse of topical corticosteroids in patients who attended dermatology venerology leprosy outpatient department. Int J Basic Clin Pharmacol 2020;9:1656-60. 